\title{
Market Definition and Market Power in Payment Card Networks:
}

\section{Some Comments and Considerations}

\author{
Lawrence J. White* \\ Stern School of Business \\ New York University \\ Lwhite@stern.nyu.edu
}

\begin{abstract}
$\underline{\text { Abstract }}$
Antitrust and regulatory concerns continue to swirl around the payment cards industry, for understandable reasons: The industry is clearly not atomistic in structure; it has substantial network characteristics and thus embodies network externalities; it involves two-sided markets; and its two most prominent members -- Visa and MasterCard -- are network joint ventures of the banks that issue credit and debit cards to individual cardholders and that enroll (acquire) and service the merchants who accept those cards.

These characteristics raise the possibility that the industry may not be fully competitive -that market power may currently be present and/or may prospectively be created or enhanced as a consequence of a merger -- and thus raise potential policy concerns. But these same characteristics also cloud the standard against which the performance of the industry should be judged. And they complicate the analysis that is necessary to form judgments.

This essay attempts to clarify some of these issues while exploring the same themes as does Emch and Thompson (2006): market definition, market power, and payment card networks.
\end{abstract}

Keywords: Antitrust, regulation, market definition, market power, mergers, monopolization, payment networks

JEL Classification Numbers: L14, L41, L43

* Address: 44 West 4th Street, New York, NY 10012-1126; Tel: 212-998-0880; Fax: 212-995-4218; E-mail: Lwhite@stern.nyu.edu 


\section{Introduction}

Antitrust and regulatory concerns continue to swirl around the payment cards industry, for understandable reasons: The industry is clearly not atomistic in structure; it has substantial network characteristics and thus embodies network externalities; it involves two-sided markets; and its two most prominent members -- Visa and MasterCard -- are network joint ventures of the banks ("issuing banks") that issue credit and debit cards to individual cardholders and the banks ("acquiring banks") that enroll (acquire) and service the merchants who accept those cards.

These characteristics raise the possibility that the industry may not be fully competitive -that market power may currently be present and/or may prospectively be created or enhanced as a consequence of a merger -- and thus raise potential policy concerns. But these same characteristics also cloud the standard against which the performance of the industry should be judged. And they complicate the analysis that is necessary to form judgments.

This essay will attempt to clarify some of these issues while exploring the same themes as does Emch and Thompson (2006): market definition, market power, and payment card networks. As background, in Section 2 we will discuss the issue of market definition for the purposes of analyzing mergers that might prospectively create or enhance market power. The market definition paradigm that has become the standard framework in antitrust merger analysis can be applied (with due recognition of their special characteristics) to payment networks. In Section 3 we again discuss market definition, but this time in the context of concerns about monopolization -- about the current existence of market power. As we will argue, the analytical framework for market definition that has worked well for well over two decades for merger analysis has substantial deficiencies in the monopolization realm. Section 4 will briefly address two-sided markets. Section 5 then addresses payment card markets and the approach taken by Emch and Thompson (2006) in analyzing market definition, mergers, and monopolization in these markets. Section 6 offers a brief conclusion. 


\section{Market Definition for Merger Analysis}

Policy concerns about the exercise of market power usually arise in one of two contexts: (a) existing market structures and/or market practices that may allow existing firms unilaterally or jointly to exercise market power; and (b) mergers that may allow the merged firm (and possibly its rivals) prospectively to exercise newly formed or enhanced market power. The assessment of existing or prospective market power usually requires the delineation (definition) of a market in which the market power might be exercised. In this section we will discuss market definition for merger analysis purposes; in the next section we will return to market definition in the context of monopolization allegations.

For over two decades, the standard approach for antitrust analysis of mergers has been that of the Horizontal Merger Guidelines, first developed by the Department of Justice's Antitrust Division in 1982. ${ }^{1}$ At the center of the Guidelines is a market delineation paradigm that, in essence, searches for the minimum number of products (distributed over geographic space and product space) that would be capable of being monopolized. It does so by focusing on demand-side substitutability, asking (for an initial, narrowly defined candidate set of products) the following question: Could a hypothetical monopolist (that was selling these products) succeed in profitably imposing a "small but significant and nontransitory increase in price" above existing levels? (This question has come to be known as the "SSNIP" test.) If the answer is yes, then the candidate set of products constitutes a relevant market for merger analysis purposes. If the answer is "no" (because too many buyers would switch away to buying other products), then the set of products is expanded and the question asked again, until a "yes" answer is reached. In essence, the SSNIP test asks if a group of products can be monopolized; if they can, then they constitute a relevant market for antitrust merger analysis.

1 The Guidelines were modified in 1984, 1992, and 1997. The current version can be found at: http://www.usdoj.gov/atr/public/201898.htm. 
Once the relevant market has been delineated, the remainder of the Guidelines analysis attempts to ascertain whether the proposed merger would be likely to allow the merged firm to exercise the market power that is central to the antitrust concern about mergers. The overall level of seller concentration (as measured by the Herfindahl-Hirschman Index), the market shares of the merging parties, the ease of expansion by smaller firms and by producers of close substitutes, entry conditions generally, the nature of the buying side of the market, the homogeneous or heterogeneous nature of the product, and the antitrust history of the industry are among the characteristics of the delineated market that are examined. ${ }^{2}$ The efficiencies promised by the merging parties are also considered, although a common problem is that such efficiencies are easy to promise ex ante but may be difficult to deliver ex post.

A good example of the use of the Merger Guidelines and its market definition paradigm can be found in FTC v. Staples, 970 F. Supp. 1066 (1997). ${ }^{3}$ In September 1996 Staples proposed to acquire Office Depot. Initially, this appeared to be a merger that would raise little antitrust concern, since most of the office products that both "office super store" (OSS) chains sold were also sold through a wide variety of other outlets, such as Wal-Mart, Kmart, grocery stores, drug stores, and stationery stores, as well as by a third OSS (Office Max). The two merging OSSs accounted for less than $10 \%$ of overall sales of these products.

However, an initial simple comparison of the prices of a standardized set of office products

\footnotetext{
2 There are two primary theories of the prospective exercise of market power that underlie this examination. One theory is "coordinated effects", which might be characterized as "traditional oligopoly theory". Thus, the worry is that the merged firm and its close rivals will find a price increase to be jointly beneficial and will find implicit (or possibly even explicit) means to achieve it. The exposition by Stigler (1964) is in this spirit. The other theory is "unilateral effects", which applies to sellers of differentiated products. Here the concern is that there may be a sufficient number of customers of one of the two merging companies whose runner-up preferences are for the product of the other company and whose preferences are sufficiently strong such that the merged firm may be able unilaterally to raise its price to these customers (if it can identify them and thus practice price discrimination) or to raise its prices overall (so that the gains from the "trapped" customers exceed the losses from other customers who turn to other sellers).

${ }^{3}$ Further discussion of this case can be found in Baker (1999), White (2002), and Dalkir and Warren-Boulton (2004).
} 
sold by the OSSs showed that prices were highest when either Staples or Office Depot was the only OSS chain in a metropolitan area, they were lower when there were two OSS chains present in a metropolitan area, and they were lower still when all three OSS chains were present in a metropolitan area. More sophisticated econometrics conducted by the FTC, which corrected for other characteristics of the metropolitan areas, upheld the finding of these differentials.

As the FTC argued, these price differentials indicated that a single OSS seller could sustain - and in fact was sustaining -- higher prices, and thus office products sold through OSSs in a metropolitan area constituted a relevant market for the purposes of analyzing the merger. Since there was only one other OSS chain and entry was perceived to be difficult, the merger would mean that the relevant metropolitan markets would consolidate from two OSSs to one (where only Staples and Office Depot were present) and from three OSSs to two (where Office Max was also present). The efficiencies that Staples and Office Depot promised seemed dubious.

Though Staples and Office Depot argued that the relevant markets were much wider than just OSSs and that the promised efficiencies were substantial, the FTC's view prevailed in court, and the merger was stopped.

With suitable modification for the complexity that is inherent in payment card networks (as will be discussed in Sections 4 and 5), the Merger Guidelines paradigm for market definition and its overall approach to preventing increases in market power seem quite applicable to these networks.

\section{Market Definition in Monopolization Cases}

In contrast to merger analysis, there is no standard paradigm for market definition in monopolization cases. And, as we will argue, the Merger Guidelines' paradigm is generally not applicable. ${ }^{4}$

In a typical monopolization antitrust challenge, a plaintiff (usually a private party but

\footnotetext{
${ }^{4}$ Further discussion of these points can be found in Nelson and White (2003) and White (2006).
} 
occasionally the government) alleges that the defendant has market power and that its practices have allowed the defendant to exclude competitors and thereby exercise that market power and charge prices that are above competitive levels. ${ }^{5}$ An initial step in this process is the specification of a market in which the defendant has a large share and is thereby implicated in exercising market power. Until the 1980s the (high) profit rates of the defendant were usually an important part of the evidence that the plaintiff would use in its argument. But the weaknesses of using standard (GAAP) accounting data for these profit calculations ${ }^{6}$ have brought them into disfavor. In principle (and subject to availability), cross-section data in local markets that would relate differing prices to differing levels of seller concentration (e.g., of the type that was found in the Staples case and that can be found in analyses of other retail markets and more generally in analyses of other goods and services with localized markets, such as railroad freight hauling, airline passenger services, hospital services, cement, etc.) could shed light on the relevant market and whether the defendant has been exercising market power. ${ }^{7}$

However, what cannot be used is the Merger Guidelines' SSNIP test. If an analysis is conducted as to whether the defendant could profitably raise its price by a "small but significant amount" from existing levels, the answer ought (for a profit-maximizing defendant) to be "no" regardless of whether the defendant truly does have market power or the defendant is merely one

\footnotetext{
${ }^{5}$ In a regulatory context, there may simply be the claim that the candidate (for regulation) firm is exercising market power and charging above-competitive prices.

${ }^{6}$ See, for example, Carlton and Perloff (2005, pp. 249-252 ) for a list and discussion of eight deficiencies in accounting data for these purposes.

${ }^{7}$ Also, as Werden (2000) has pointed out, the Merger Guidelines market definition paradigm can be used if the legal action is being undertaken so as to stop a prospective action by the defendant -- e.g., the plaintiff is seeking a preliminary injunction to enjoin a proposed action that the plaintiff alleges will allow the defendant to exercise market power. In this case, the same forward-looking perspective of the Merger Guidelines -- will this action make things worse? will the defendant's prospective action allow it to impose a "small but significant nontransitory increase in price"? -- can be brought to bear. But most antitrust and regulatory concerns with monopolization involve complaints about the current existence of market power and not its nascent formation.
} 
among many firms in a differentiated product market. Thus, the question is useless for the task at hand.

Unfortunately, there has not been sufficient realization that the SSNIP test is inappropriate for monopolization cases. ${ }^{8}$ Further, the loose language that economists sometimes use to describe monopolies and their powers -- e.g., that a monopoly has the power to raise the price over competitive levels (rather than that the monopoly has the power to maintain the price at a level that is above competitive levels) -- tends to encourage the (misguided) notion that a SSNIP test would be an appropriate test.

Perhaps the best illustration of a legal decision going off-course because of the inappropriate asking of this question is in U.S. v. E.I. du Pont de Nemours \& Co., 118 F. Supp. 41 (1953), 351 U.S. 377 (1956). In December 1947 the U.S. Department of Justice's Antitrust Division charged du Pont with monopolization of the cellophane market. The company had a 76\% share of cellophane sales and indirectly controlled the remaining $24 \%$ through a licensing agreement with the other seller of cellophane (Sylvania Industrial Corporation of America). Du Pont, in its defense, claimed that the relevant market was instead "flexible wrapping materials" (including kraft paper, waxed paper, aluminum foil, polyethylene, pliofilm, glassine, parchment, Saran, and cellulose acetate, as well as cellophane), of which its sales accounted for only $18 \%$.

Both the initial trial court in its 1953 decision and the Supreme Court on appeal in its 1956 decision $^{9}$ endorsed du Pont's position. Both decisions emphasized that du Pont faced competition from other flexible wrapping materials and was thereby constrained from raising its price of cellophane. But, of course, du Pont (if it was maximizing profits on behalf of its shareholder-

\footnotetext{
${ }^{8}$ Nelson and White (2003) provide examples of prominent economists and prominent legal decisions that have made the mistake of asking this question in a monopolization context.

${ }^{9}$ The Supreme Court's decision in favor of du Pont was by a 4-3 vote.
} 
owners) should have already been maintaining its cellophane prices at levels at which a further increase would have been unprofitable; in essence, it would be constrained by the prices of substitutes from being able to raise its price profitably from observed levels, regardless of whether the relevant market was cellophane and du Pont was exercising market power or the relevant market was flexible wrapping materials and du Pont was not exercising market power. ${ }^{10}$ This mis-directed analysis has since come to be known as "the cellophane fallacy".

Unfortunately, with the SSNIP test ruled out, profitability data in disfavor, and cross-section price-concentration data often not available, the issue of market definition for monopolization analysis remains as one that is desperately in need of a paradigm. This need for a paradigm applies equally well to the area of payments networks. Though the Merger Guidelines paradigm will adequately handle the issue of a merger between payments networks (e.g., a merger between American Express and Discover), suppose instead that the issue is the current exercise of market power. Does American Express currently exercise market power? Does Discover? Does Visa or MasterCard? How could we tell?

\section{Two-sided markets}

At first-glance, two-sided markets (of which payment networks are clearly an example), where there are positive demand externalities that extend between the two markets, may appear exotic and difficult to comprehend. However, newspapers and other publications where the firm's revenues come from a mixture of subscriptions (and/or per-unit sales) and advertising are a familiar example; cable television is another; more recently, movie exhibition (where advertisements that precede the

\footnotetext{
${ }^{10}$ In their critique of the District Court's decision, Stocking and Mueller (1955) pointed out that du Pont's profits from cellophane were substantially larger than its profits from rayon, where it faced 15-18 other producers of a commodity product and where its market share (less than 20\%) was approximately the same as its $18 \%$ share of the "flexible wrapping materials" market; they also pointed out that du Pont's price of cellophane moved independently of the prices of other flexible wrapping materials.
} 
feature presentation have become pervasive) is yet another.

In all of these instances, the enterprise has to determine the profit maximizing balance between the subscription (or per-unit) price and the advertising fees and their consequences for attracting/deterring numbers of readers/viewers on the one hand and advertisers on the other, as well as determining the type and mix of content that will appeal to readers/viewers (and thus appeal to advertisers as well). ${ }^{11}$ When set in this context, the issues are less exotic and more manageable. As we will argue, the same can be said for payment networks.

The positive externalities between the markets of the enterprises of this type mean that the standard normative prescription of price equal to marginal cost no longer holds for each market considered separately. Instead, the positive externalities also have to be taken into account. Further, in considering how a merger might affect pricing, again the positive externalities have to be included in the analysis, and the net effects of both prices should be considered. ${ }^{12}$

\section{Payment networks}

Because the terminology and the tracking of "who does what and to whom" in payment networks can be confusing, a few diagrams may prove useful. In Figure 1 we portray a simple payment card network: a charge/credit card network in which the cardholder buys goods/services (the solid line) from the merchant and makes payments through the network (the dashed line); network owner/operator deals directly with the cardholder and with the merchants that accept the card. ${ }^{13}$ The

\footnotetext{
${ }^{11}$ If we use newspapers and other periodicals as an example, it is apparent that the mix of editorial content and advertising can range from a pattern of all editorial content and zero advertising (e.g., Consumer Reports) to a pattern of zero editorial content and all advertising (e.g., local "shoppers" and classified ad periodicals), and the prices charged to readers for the periodicals themselves are usually positive but can encompass a range that includes zero (with all of the revenue support for the periodical coming from advertising).

${ }^{12}$ General discussions of two-sided markets can be found in, for example, Evans (2003), Wright (2004), and Roson (2005).

${ }^{13}$ This is sometimes described as a "proprietary" network; see, e.g., Evans and Schmalensee (1999), Schmalensee
} 
market is two-sided: The network is interested in attracting credit/charge cardholders, who will use their cards to buy goods and services from card-accepting merchants (with an extension of credit to the cardholder from the network owner); and it is interested in attracting merchants, for whom the network's provision of credit to customers may substitute for the merchant's extending credit (and the attendant costs to the merchant), as well as the network's payment to the merchant substituting for the cash or check payments from customers (and their attendant costs). The greater are the number of cardholders, the more attractive is the network to the merchant (who must bear some fixed costs of set-up, such as card readers, as well as any per-transaction fees); and the more merchants that are part of the network and accept the card, the more attractive is the card to the cardholder. $^{14}$

At the center of the network is the network owner. And it is clear that the network owner can charge fees -- positive or negative -- to cardholders and to merchants so as to find the best combination (indicated by the sum of $f_{p n}+t_{p n}$ within the central box of Figure 1) that will maximize the overall profitability of the network. The fees portrayed in the figure are levied per transaction; but there can also be fixed fees (on cardholders and/or merchants) as well as special charges.

The framework portrayed in Figure 1 basically describes the structure of the American Express and Discover networks until quite recently. ${ }^{15}$

(2002), and Rochet and Tirole (2002); see also Hunt (2003) and Chakravorti (2003).

\footnotetext{
${ }^{14}$ In the language of Economides and White (1994), this is a one-way network, in the sense that the goods flow only in one direction, and the payments flow only in the other direction. (This is in contrast, say, with a telephone network, in which the flows of communications can go in either direction between any two members of the network.) Unlike a twoway network, where there are direct externalities -- an additional member of a network conveys direct benefits to the other members (in a telephone network, the other members can call and be called by the new members (Rohlfs 1974, 2001)) -- in a one-way network the externalities are indirect: An existing cardholder gets no direct benefit when an additional cardholder joins the network; the benefits come indirectly, as a consequence of more merchants accepting the card when there are more cardholders. Similarly, a merchant that already accepts the card gets no direct benefit when another merchant decides to accept the card; again, the benefits come indirectly, as a consequence of more consumers deciding to use the card when there are more merchants that accept the card.

${ }^{15}$ As a consequence of the Justice Department's victory in U.S. v. Visa USA Inc., 163 F. Supp.2d 322 (2001), 344
} 
Figure 2 is somewhat more complicated, since it brings into the picture banks for dealing with cardholders and with merchants and the network owners (Visa and MasterCard) as the connection between the banks. A further complication is the fact that Visa and MasterCard are themselves joint ventures of the banks that participate in their networks. Also, since banks are now in the picture, the diagram can also represent debit card networks. ${ }^{16}$ Further, with three entities between the cardholder's payment and the merchant's receipt of payment, there are now the possibility of four layers of fees. ${ }^{17}$ One fee in particular -- the "interchange" fee -- is the fee (specified by the network) that must be paid by the acquiring bank to the issuing bank (through the network). ${ }^{18,19}$

F.3d 229 (2003), the two networks can now use banks as their intermediaries. Prior to that victory, both Visa and MasterCard had membership rules that forbade member banks in the U.S. from issuing Discover or American Express cards.

\footnotetext{
${ }^{16}$ Also, the diagram could readily encompass automatic teller machine (ATM) networks, except the "merchant" would be replaced by the ATM and the flow of goods replaced by a flow of immediate cash.

${ }^{17}$ If the issuing and acquiring banks are fully competitive and efficient, then their presence adds no complications and Figure 2 can be collapsed down to Figure 1. Since Visa and MasterCard are joint ventures of the participating banks, it might seem that the competitive nature of the banks might preclude the exercise of market power by either network: If the network levied fees and then rebated the fees to the banks/owners in proportion to a bank's activity in the network, then the bank would include the rebate in its calculations of marginal revenues and thus would expand its activity and lower its price and thereby pass through the network fees back to cardholders and/or merchants. But if the network fees are passed back to the banks/owners in ways that are not proportional to activity, they would not become part of a bank's marginal calculations, and the network could become the vehicle for the constituent banks jointly to reap the gain from the network's exercise of market power. See Lewis and Reynolds (1979).
}

${ }^{18}$ In Figure 2, the interchange fee is best represented by $t_{\mathrm{ib}}$. As Emch and Thompson (2006) and Schmalensee (2002) point out, there is no necessary reason why the interchange fee has to be paid by the acquiring bank to the issuing bank. It could be paid in the opposite direction, depending on what maximizes the profitability of the network. In Australia, the interchange fees for PIN debit cards are paid in this "reverse" direction. And the same is true for ATM networks in the U.S.; for the latter, see McAndrews (2003).

${ }^{19}$ It is sometimes claimed that the interchange fee is required to be paid by the merchant to the issuing bank (and it is thus described in Emch and Thompson (2006)); but in reality the fee is set by the network for payment between categories of banks. Since the acquiring banks are near-universally considered to be highly competitive, the interchange fee is generally passed through entirely to merchants, thus giving rise to the (false) impression that it is levied directly on the merchants. 
Despite these complications, the basic idea remains of the two-sided market, the positive externalities between cardholders and merchants, and the network owner's interest in finding the set of net fees to cardholders and to merchants that maximizes the overall value of the network.

We can now use this framework and discussion to address the issues raised by Emch and Thompson (2006). First, their model is closest in spirit to that portrayed here in Figure 1. There are no complications of joint ownership of the network or of market power by issuing banks or acquiring banks. Second, consistent with the figure, their model is one of fixed proportions (which greatly simplifies the two-sided market analysis) and simple per-transaction fees along the lines indicated. Though their model encompasses three fees (an issuer switch fee, a merchant switch fee, and an interchange fee), one of these fees is clearly redundant, as they acknowledge.

Third, Emch and Thompson's merger analysis is in the spirit of the Merger Guidelines but also encompasses the two-sided markets insights. As a consequence of a merger between two payments networks of the kind portrayed in Figure 1, either or both net prices could be affected. As their model indicates, if merchants will accept any card so long as the net fee of a card is less than the merchant's costs of handling cash while cardholders choose networks on the basis of price, then an anticompetitive merger leaves the merchants' fee unchanged and causes the fee charged to cardholders to increase. In essence, if the merchants' behavior allows them to be already subjected (pre-merger) to limit pricing, then the post-merger exercise of market power must manifest itself in the other (cardholder) market. At the other extreme, if merchants choose among networks depending on fees while cardholders accept any card with costs that are less than those of handling cash, then the anticompetitive merger leaves fees to cardholders unchanged and causes fees to merchants to increase. Again, the pre-merger existence of limit pricing on (this time) the cardholder side of the market dictates that the post-merger exercise of market power is manifested on the other side. Finally, under a third set of assumptions Emch and Thompson show that with Bertrand 
behavior among commodity-like networks, only a merger to monopoly will allow the net exercise of market power.

There are at least three important network issues that Emch and Thompson do not address. First, their model is partial equilibrium in nature, since merchants' pricing of their goods and services are assumed to be unchanged throughout. It would be interesting to see what changes might occur if this restraint were lifted. Second, the issue of the interchange fee's being set collectively by the joint venture members of the Visa and MasterCard networks -- rather than, say, on a negotiated basis between individual acquiring and issuing banks -- is not addressed in the Emch and Thompson model, since they opt for the simple structure of Figure 1. But it is the collective nature of the interchange fee-setting in the Visa and MasterCard networks that has attracted so much regulatory and antitrust attention around the world. ${ }^{20}$ Third, the keynote question of delineating the relevant market with respect to payment networks for the consideration of monopolization claims in an antitrust context or a regulatory context is not addressed in the Emch and Thompson framework. Their comparative statics with respect to the number of networks provides the type of information that would be useful for a Merger Guidelines analysis. But how would an analyst, observing the existing payment networks, be able to conclude that any individual network (or some, or all) was exercising market power? Emch and Thompson have no ready answer to this important question.

\section{Conclusion}

Payment networks, antitrust, and regulation are likely to continue to be intertwined, for the reasons discussed in this essay. For the purposes of merger analysis, the complexity (including two-sided

\footnotetext{
${ }^{20}$ As is clear from the portrayal in Figure 1, for an integrated ("proprietary") network like Discover or American Express the setting of the "interchange fee" is simply a unilateral maximizing decision. It is an interesting hypothetical question to ask whether the interchange fees of the Visa and MasterCard networks would have attracted as much public policy attention if the two networks were not joint ventures by their participant banks but instead were simply freestanding separately owned networks.
} 
markets) of payments networks need not interfere with the straightforward and sensible application of the Horizontal Merger Guidelines and specifically the market delineation paradigm that is at the heart of the Guidelines. Once we leave merger analysis and try to deal with issues of market delineation and the exercise of market power in an ongoing antitrust or regulatory context, however, there are few analytical aids to help. A major task of antitrust and regulatory analysis, for payments networks and for monopolization analysis more generally, must be to develop a workable paradigm of market delineation for such investigations.

\section{$\underline{\text { References }}$}

Baker, Jonathan B. (1999) "Econometric Analysis in FTC v. Staples," Journal of Public Policy \& Marketing, 18 (Spring): 11-21.

Carlton, Dennis W. and Jeffrey M. Perloff (2005) Modern Industrial Organization, 4th edn. New York: Pearson.

Chakravorti, Sujit (2003) "Theory of Credit Card Networks: A Theory of the Literature," Review of Network Economics, 2 (June): 50-78.

Dalkir, Serdar and Frederick R. Warren-Boulton (2004) "Prices, Market Definition, and the Effects of Merger: Staples-Office Depot (1997)," in John E. Kwoka, Jr., and Lawrence J. White, eds., The Antitrust Revolution: Economics, Competition, and Policy, 4th edn.. New York: Oxford University Press: 52-72.

Economides, Nicholas and Lawrence J. White (1994) "Networks and Compatibility: Implications for Antitrust," European Economic Review, 38 (April): 651-662.

Emch, Eric and T. Scott Thompson (2006) "Market Definition and Market Power in Payment Card Networks," Review of Network Economics, 5 (this issue).

Evans, David S. (2003) "Some Empirical Aspects of Multi-Sided Platform Industries," Review of Network Economics, 2 (September): 191-209.

Evans, David S. and Richard L. Schmalensee (1999) Paying with Plastic: The Digital Revolution in Buying and Borrowing. Cambridge, Mass.: MIT Press. 
Hunt, Robert M. (2003) "An Introduction to the Economics of Payment Card Networks," Review of Network Economics, 2 (June): 80-96.

Lewis, Lucinda M. and Robert J. Reynolds (1979) "Appraising Alternatives to Regulation for Natural Monopolies," in Edward J. Mitchell, ed., Oil Pipelines and Public Policy. Washington, D.C.: American Enterprise Institute: 135-140.

McAndrews, James J. (2003) "Automated Teller Machine Pricing -- A Review of the Literature," Review of Network Economics, 2 (June): 146-158.

Nelson, Philip B. (2003) "Market Definition and the Identification of Market Power in Monopolization Cases: A Critique and a Proposal," Working Paper \#EC-03-26, Stern School of Business, New York University; available at:

http://www.stern.nyu.edu/eco/wkpapers/marketdefinition.pdf

Rochet, Jean-Charles and Jean Tirole (2002) "Cooperation among Competitors: Some Economics of Payment Card Associations," Rand Journal of Economics, 33 (Winter): 549-570.

Rohlfs, Jeffrey (1974) "A Theory of Interdependent Demand for a Communications Service," Bell Journal of Economics and Managerial Science, 5 (Spring): 16-37.

Rohlfs, Jeffrey (2001) Bandwagon Effects in High Technology Industries. Cambridge, Mass.: MIT Press.

Roson, Roberto (2005) "Two-Sided Markets: A Tentative Survey," Review of Network Economics, 4 (June): 142-160.

Schmalensee, Richard (2002) "Payment Systems and Interchange Fees," Journal of Industrial Economics, 50 (June): 103-122.

Stigler, George J. (1964) "A Theory of Oligopoly," Journal of Political Economy, 72 (February): 5569.

Stocking, George W. and Willard F. Mueller (1955) "The Cellophane Case and the New Competition," American Economic Review, 45 (March): 29-63.

Werden, Gregory J. (2000) "Market Delineation under the Merger Guidelines: Monopoly Cases and Alternative Approaches," Review of Industrial Organization, 16 (March): 211-218.

White, Lawrence J. (2000) "Present at the Beginning of a New Era for Antitrust: Reflections on 1982-1983." Review of Industrial Organization, 16 (March): 131-149. 
White, Lawrence J. (2000) "Staples-Office Depot and UP-SP: An Antitrust Tale of Two Proposed Mergers," in Daniel J. Slottje, ed., Measuring Market Power. Amsterdam: North-Holland: 153-174.

White, Lawrence J. (2006) "Market Definition in Monopolization Cases: A Paradigm is Missing," in Wayne D. Collins, ed., Issues in Competition Law and Policy. Chicago: American Bar Association (forthcoming); available as Working Paper \#EC-05-18, Stern School of Business, New York University: http://www.stern.nyu.edu/eco/wkpapers/LW.pdf

Wright, Julian (2004) "One-Sided Logic in Two-Sided Markets," Review of Network Economics, 3 (March): 44-64. 


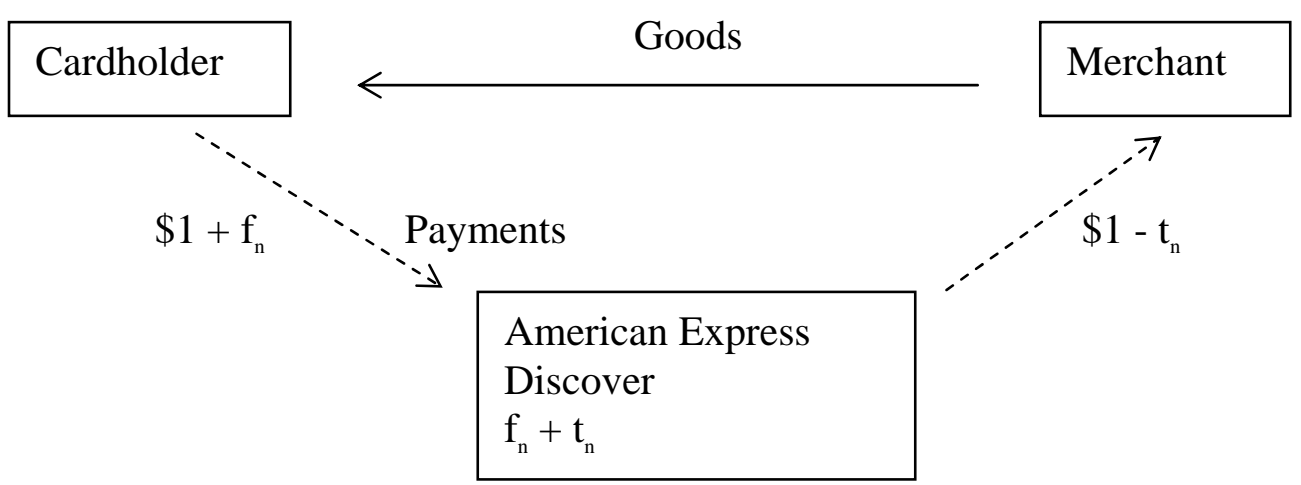

$\leftarrow$ : Flow of goods

$<---$ : Flow of payments

$\mathrm{f}_{\mathrm{n}}=$ net fee (positive or negative) paid by card holder to network owner

$t_{n}=$ net fee (positive or negative) paid by merchant to network owner

Figure 1: A Simple Payment Card Network without Banks 


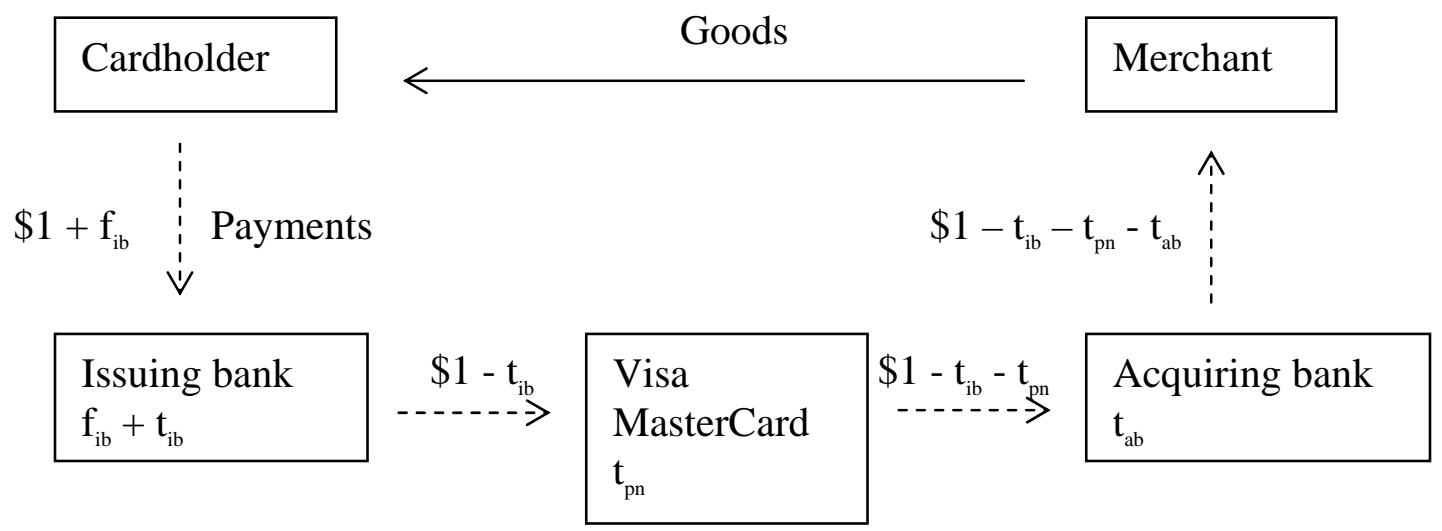

\footnotetext{
$\leftarrow$ : Flow of goods

$<---$ : Flow of payments

$\mathrm{f}_{\mathrm{ib}}=$ net fee (positive or negative) paid by card holder to issuing bank

$\mathrm{t}_{\mathrm{ib}}=$ net fee (positive or negative) received by issuing bank from network

$\mathrm{t}_{\mathrm{pn}}=$ net fee received by Visa (or Mastercard) from acquiring bank

$\mathrm{t}_{\mathrm{ab}}=$ net fee received by acquiring bank from merchant
}

Figure 2: A More Complex Payment Card Network Involving Banks and a Coordinating Entity 